\title{
Thrombus Formation Inhibition of Esculetin through Regulation of Cyclic Nucleotides on Collagen-Induced Platelets
}

\author{
Dong-Ha Lee ${ }^{\dagger, *}$ \\ Department of Biomedical Laboratory Science, Molecular Diagnostics Research Institute, \\ Namseoul University, Chungcheongnam-do 31020, Korea
}

\begin{abstract}
Physiological agents trigger a signaling process called "inside-out signaling" and activated platelets promote adhesion, granule release, and conformational changes of glycoprotein $\mathrm{IIb} / \mathrm{IIIa}\left(\alpha \mathrm{IIb} / \beta_{3}\right)$. Activated $\alpha \mathrm{IIb} / \beta_{3}$ interacts with fibrinogen and initiates a second signaling step called "external signaling". These two signaling pathways can cause hemostasis or thrombosis, and thrombosis is a possible medical problem in arterial and venous vessels, and platelet-mediated thrombosis is a major cause of cardiovascular disease (CVD). Therefore, modulating platelet activity is important for platelet-mediated thrombosis and cardiovascular disease. Esculetin is a coumarin-based physiologically active 6,7-dihydroxy derivative known to have pharmacological activity against obesity, diabetes, renal failure and CVD. Although some studies have confirmed the effects of esculetin in human platelet activation and experimental mouse models, it is not clear how esculetin has antiplatelet and antithrombotic effects. We confirmed the effect and mechanism of action of escultein on human platelets induced by collagen. As a result, esculetin decreased $\mathrm{Ca}^{2+}$ recruitment through upregulation of inositol 1, 4, 5-triphosphate receptor. In addition, esculetin upregulates cyclic adenosine monophosphate (cAMP) and cyclic guanosine monophosphate (cGMP)-dependent pathways and inhibits fibrinogen binding and thrombus contraction. Our results demonstrate the antiplatelet effect and antithrombotic effect of esculetin in human platelets. Therefore, we suggest that esculetin could be a potential phytochemical for the prevention of thrombus-mediated CVD.
\end{abstract}

Key Words: Esculetin, cAMP/cGMP, Intracellular $\mathrm{Ca}^{2+}$, Fibrinogen binding, Fbrin clot

\section{서 론}

정상적인 순환에서 collagen 섬유는 혈소판에 결합할 수 없지만 내피 벽이 손상되어 collagen 섬유가 노출되게 되면, collagen 섬유가 혈소판 막 수용체의 integrin $\alpha_{2} \beta_{1}$ 및 glycoprotien VI에 결합함으로써 inside-out signaling 경로를 통해 혈소판의 활성화를 유도한다(Chen and Kahn, 2003). 혈소판 활성화가 일어나면, 세포질 내 phospholipase $\mathrm{C} \gamma 2$ 는 phosphatidylinositol 4,5 bisphosphate를 inositol diacylglycerol
과 1,4,5-trisphosphate $\left(\mathrm{IP}_{3}\right)$ 로 가수분해 되는데, 내피벽이 손상되면 collagen이 노출되어 혈소판의 integrin $\alpha_{2} \beta_{1}$ 및 glycoprotien VI에 결합함으로써 혈소판 활성화가 일어나는 동안 phospholipase $\mathrm{C} \gamma 2$ 는 phosphatidylinositol 4,5 bisphosphate를 inositol diacylglycerol과 1,4,5-trisphosphate $\left(\mathrm{IP}_{3}\right)$ 로 분해하고, $\mathrm{IP}_{3}$ 는 소포체로부터 칼슘을 세포질 내로 이동시 킨다(Farndale, 2006). 활성화된 혈소판에서 이러한 신호 전 달 이벤트는 glycoprotein $\mathrm{Ilb} / \mathrm{IIII}$ (integrin $\alpha \mathrm{Ilb} / \beta_{3}$ )의 구조적 변화를 일으켜 혈전 형성 및 혈소판 매개 혈전 수축을 유 발합니다(Phillips et al., 2001). 따라서 혈소판은 지혈에 필

Received: October 5, 2021 / Accepted: November 22, 2021

*Professor.

${ }^{\dagger}$ Corresponding author: Dong-Ha Lee. Department of Biomedical Laboratory Science, Molecular Diagnostics Research Institute, Namseoul University, 91, Daehak-ro, Seonghwan-eup, Seobuk-gu, Cheonan-si, Chungcheongnam-do 31020, Korea.

Tel: +82-41-580-2148, Fax: 041-580-2932, e-mail: dhlee@nsu.ac.kr

(C) The Korean Society for Biomedical Laboratory Sciences. All rights reserved.

(C) This is an Open Access article distributed under the terms of the Creative Commons Attribution Non-Commercial License (http:/creativecommons.org/licenses/by-nc/3.0/) which permits unrestricted non-commercial use, distribution, and reproduction in any medium, provided the original work is properly cited. 
수적인 요소인 동시에 혈전증의 위험을 내포하고 있습니 다. CVD 환자의 혈전증을 효과적으로 감소시키기 위해 항혈소판제가 이용되기 있지만 일부 약물들의 부작용들 도 보고되고 있다(Jackson, 2011). 따라서 새로운 항혈소판 제 개발을 위해 다양한 약용식물의 항혈소판 활성에 주 목하고 있다. 또한, 최근 코로나19 백신으로 뇌정맥동 혈 전증(CVST), 출혈성 뇌졸중 등의 부작용 사례가 보고되 고 있어, 향후 코로나 19 백신의 사용에 항혈전제의 병행 사용을 위해서라도 안정적인 항혈전 성분의 규명이 시급 하다(Kantarcioglu et al., 2021).

정상적인 혈액 순환에서 내피 세포는 비활성 혈소판 상태를 유지하는 nitric acid와 prostaglandin $\mathrm{I}_{2}$ 를 방출하는 데, 이 물질들은 혈소판에 작용하여 cAMP 및 cGMP 수 준을 증가시킨다. 이 중 cAMP은 protein kinase A (PKA) 의 활성화를, $\mathrm{cGMP}$ 는 protein kinase $\mathrm{G}(\mathrm{PKG})$ 의 활성화를 유도하여 vasodilator-stimulated phosphoprotein (VASP) 및 inositol 1,4,5-triphosphate receptor $\left(\mathrm{IP}_{3} \mathrm{R}\right)$ 의 인산화를 일으킨 다(Schwarz et al., 2011). $\mathrm{IP}_{3} \mathrm{R}$ 의 인산화를 통해 $\mathrm{IP}_{3} \mathrm{R}$ 의 비 활성화가 이루어지며, 이는 dense tubular system으로부터 세포질 내로의 $\mathrm{Ca}^{2+}$ 동원을 억제하는 결과를 초래한다 (Cavallini et al., 1996; Quinton and Dean, 1992). 혈소판에서, $\mathrm{VASP}$ 는 cAMP-의존성인 VASP $\mathrm{Ser}^{157}$ 및 cGMP-의존성인 VASP Ser ${ }^{239}$ 가 있으며 이들의 인산화가 일어날 때, $\alpha \mathrm{IIb} / \beta_{3}$ 활성화 및 actin filament 활성이 억제되는 것으로 보고된 바 있다(Laurent et al., 1999; Sudo et al., 2003). 따라서, cyclic nucleotides를 조절하는 약용 식물은 혈소판 매개 혈전증 에 사용될 가능성이 있다.

Scopolia나 Artemisia 속의 식물 뿌리에 주로 함유되어 있다고 보고된 esculetin은 항당뇨, 항염즘, 항암 등의 여러 약리학적 효과를 가지고 있다(Karthika et al., 2012). 몇몇 연구에 따르면, esculetin은 심혈관계에 보호 효과 가 있다고 보고되었고, esculetin을 경구로 전처리 하였 을 때 isoproterenol로 유도한 심근경색증의 쥐에서 antilipoperoxidative 효과를 나타내었으며, 이는 free radical 소 거 특성 때문일 것으로 보았다(Liang et al., 2017). 다른 연 구에서 esculetin의 효과는 사람 혈소판 활성화 및 실험적 마우스 모델에서 조사되었으며, esculetin은 collagen 및 arachidonic acid로 유도한 사람 혈소판의 응집을 억제하기 도 하였다(Hsia et al., 2019). 그러나, thrombin 및 U46619와 같은 다른 작용제에는 효과가 나타나지 않았고, esculetin 가 혈소판 활성을 억제하는 기전도 불분명한 상태이다. 본 연구는 collagen 유도의 혈소판에서 esculetin가 cyclic

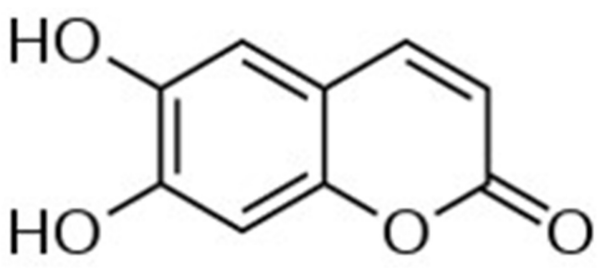

Fig. 1. The structure of esculetin. PIN: 6,7-Dihydroxy-2H-1benzopyran-2-one, Chemical formula: $\mathrm{C}_{9} \mathrm{H}_{6} \mathrm{O}_{4}$, Molar mass: $178.14 \mathrm{~g} / \mathrm{moL}$

nucleotides 및 관련 신호 분자를 조절함으로써 혈소판 활 성화 및 혈전 형성을 억제하는지를 확인하였다.

\section{재료 및 방법}

\section{시료}

Avention Corporation (Incheon, Korea)에서 Esculetin을 제공하였다(Fig. 1). Collagen은 Chrono-Log Corporation (Havertown, PA, USA)로부터 제공받았고, cAMP과 cGMP Enzyme Immunoassay (EIA) kits, serotonin EIA kit 및 ATP assay kit는 Cayman Chemical (Ann Arbor, Miami, USA)로부 터 구입하여 사용하였다. Invitrogen (Eugene, OR, USA)으 로부터 Alexa Fluor 488-conjugate fibrinogen과 Fura 2-AM을 제공받았다. Westen blotting에 이용되는 antibody들은 Cell Signaling (Beverly, MA, USA)에서 구입하여 사용하였다. Enhanced chemiluminescence solution (ECL) 및 polyvinylidene difluoride (PVDF) membrane의 시약은 General Electric Healthcare (Chalfont St. Giles, Buckinghamshire, UK)로부터 확보하였다.

\section{사람 혈소판 부유액 준비}

대한 적십자사 혈액원(Suwon, Korea)에서 제공받은 사 람의 혈소판 풍부 혈장(PRP)으로 실험을 수행하였다. 세 척 혈소판은 기존의 준비 방법에 따라서 준비되었다(Shin et al., 2019). PRP를 $1,300 \times \mathrm{g}$ 로 10 분 동안 원심분리하 고, 하층의 혈소판을 획득하여 세척완충액 $(138 \mathrm{mM} \mathrm{NaCl}$, $12 \mathrm{mM} \mathrm{NaHCO}_{3}, 2.7 \mathrm{mM} \mathrm{KCl}, 5.5 \mathrm{mM}$ glucose, $0.36 \mathrm{mM}$ $\mathrm{NaH}_{2} \mathrm{PO}_{4}$, 및 $1 \mathrm{mM} \mathrm{Na} 2 \mathrm{EDTA}, \mathrm{pH}$ 6.9)로 2번 세척하였다. 이후 현탁완충액 $\left(138 \mathrm{mM} \mathrm{NaCl}, 12 \mathrm{mM} \mathrm{NaHCO}{ }_{3}, 2.7 \mathrm{mM}\right.$ $\mathrm{KCl}, 5.5 \mathrm{mM}$ glucose, $0.36 \mathrm{mM} \mathrm{NaH}_{2} \mathrm{PO}_{4}, 0.25 \%$ gelatin, $\mathrm{pH}$ 7.4)을 사용하여 최종적으로 $10^{8} \mathrm{cells} / \mathrm{mL}$ 가 되게 재구성하 였다. 저온에서 혈소판 응집이 유발될 수 있기에 상기의 모든 과정을 실온에서 진행하였으며, 남서울대학교 In- 
stitutional Review Board (IRB)의 승인(1041479-HR-201803003)을 거쳐 실험이 이루어졌다.

\section{Cyclic nulceotides(cAMP 및 cGMP) 생성량의 측정}

세척한 사람 혈소판에 다양한 농도의 esculetin를 전 처리하였다. $37^{\circ} \mathrm{C}$ 에서 3 분간 배양하고, $2 \mathrm{mM}$ 의 $\mathrm{CaCl}_{2}$ 를 첨가한 다음, $2.5 \mu \mathrm{g} / \mathrm{mL}$ 의 collagen를 첨가해주어 5 분 동 안 반응하였다. $1 \mathrm{M}$ 의 $\mathrm{HCl}$ 를 첨가하여 반응을 정지하였 고, cAMP 및 cGMP ELISA kits를 사용하여 ELISA-reader (Molecular devices, San Jose, CA, USA)에서 cAMP 및 cGMP 수준을 측정하였다.

\section{세포 내 $\mathrm{Ca}^{2+}$ 동원량의 측정}

$5 \mu \mathrm{M}$ 의 Fura 2-AM를 PRP에 넣고 $37^{\circ} \mathrm{C}$ 에서 60 분 동안 배양한 다음, 세척 완충액으로 2 번 세척하였다. 이 후, 현 탁완충액으로 최종 농도가 $10^{8} \mathrm{cell} / \mathrm{s} / \mathrm{mL}$ 가 되도록 재구성 하고, 다양한 농도의 esculetin을 전처리하였다. $37^{\circ} \mathrm{C}$ 에서 3 분 동안 배양하고, $2 \mathrm{mM} \mathrm{CaCl}_{2}$ 를 첨가한 다음, $2.5 \mu \mathrm{g}$ / $\mathrm{mL}$ 의 collagen로 첨가해 주어 5 분 동안 반응하였다. BioTeck Instrument사(Winooski, Vermont, USA)의 형광분광광 도계(SFM 25, USA)로 초기 값 340 380 nm의 여기파장 과 $510 \mathrm{~nm}$ 의 방출 파장에서 Fura 2의 형광을 측정하였다. Grynkiewicz의 방법을 이용하여 세포질로 동원되는 $\mathrm{Ca}^{2+}$ 을 산출하였다(Grynkiewicz et al., 1985).

\section{혈소판 막 $\alpha$ llb/ $\beta_{3}$ 에 대한 fibrinogen binding 정도의 측정}

세척된 사람 혈소판에 다양한 농도의 esculetin을 전 처리하였다. $37^{\circ} \mathrm{C}$ 에서 3 분간 배양하고, $2 \mathrm{mM}$ 의 $\mathrm{CaCl}_{2}$ 를 첨가한 다음, $2.5 \mu \mathrm{g} / \mathrm{mL}$ 의 collagen와 $15 \mu \mathrm{g} / \mathrm{mL}$ 의 Alexa Flour 488-human fibrinogen와 첨가해주어 5 분 동안 반응 하였다. $0.5 \%$ paraformaldehyde가 함유된 phosphate-buffered saline ( $\mathrm{pH}$ 7.4)를 첨가함으로써 반응을 정지하였고, $\mathrm{BD}$ Bioscience 사(San Jose, CA, USA)의 유세포 분석기(FACS) 로 fibrinogen binding 정도를 측정하였다. 항체가 가진 형 광을 유지시키기 위하여 상기의 과정을 어두운 환경에서 진행하였고, Cell-Quest software (BD Biosciences)를 분석프 로그램으로 사용하였다.

\section{혈소판이 매개한 fibrin clot 형성능 측정}

$400 \mu \mathrm{L}$ 의 PRP를 polyethylene tube로 옮긴 다음, 여러 농 도의 esculetin을 전처리하였다. $37^{\circ} \mathrm{C}$ 에서 3 분간 배양하고 $2 \mathrm{mM}$ 의 $\mathrm{CaCl}_{2}$ 를 첨가한 다음, fibrin clot 형성을 유발하기
위해 $0.05 \mathrm{U} / \mathrm{mL}$ 의 thrombin를 넣어 $37^{\circ} \mathrm{C}$ 에서 15 분 동안 하였다. Fibrin clot의 이미지를 디지털 카메라로 촬영하였 고, Image J Software (v1.46, National Institutes of Health, USA) 의 프로그램으로 fibrin clot이 형성된 면적을 계산하였다.

\section{Immunoblotting}

세척한 사람 혈소판에 다양한 농도의 esculetin를 전처 리하였다. $37^{\circ} \mathrm{C}$ 에서 3 분간 배양하고, $2 \mathrm{mM}$ 의 $\mathrm{CaCl}_{2}$ 를 첨 가한 다음, $2.5 \mu \mathrm{g} / \mathrm{mL}$ 의 collagen를 첨가해주어 5 분 동안 반응하였다. 같은 양의 lysis buffer를 첨가하여 반응을 정 지하였고, BCA assay kit (Pierce Biotechnology, Illinois, USA) 로 단백질 농도를 정량하였다. $20 \mu \mathrm{g}$ 의 단백질을 함유한 혈소판 용해물을 SDS-PAGE $(8 \%)$ 에서 전기영동하였고, PVDF membrane으로 옮겨서 항체반응을 진행하였다. 1 차 항체는 $1: 1,000$ 의 희석배수의 1 차 항체와 $1: 2,000$ 의 희 석배수의 2 차 항체로 반응시킨 다음. ECL 시약(General Electric Healthcare, Buckinghamshire, UK)으로 시각화를 유 발한 후, Image J Software (v1.46, National Institutes of Health, USA)의 프로그램으로 밴드의 면적을 계산하였다.

\section{통계 분석}

4 회 이상의 반복 실험을 하였고 평균 \pm 표준 편차로 실 험 결과를 표시해 주었다. 각 그룹 간의 차이는 Student's $t$-test 또는 ANOVA를 이용하여 분석하였고, $P<0.05$ 인 경 우는 통계적으로 유의한 것으로 보았다. 분산 분석에 따 라 그룹 평균 간에 유의한 차이가 있을 경우에는 Scheffe 의 방법을 이용하여 각 그룹을 비교분석하였다.

\section{결과 및 고찰}

\section{Cyclic nucleotides 생성에 미치는 esculetin의 효과}

이전의 연구를 통해, cyclic nucleotides(cAMP 및 cGMP) 가 cAMP- 및 cGMP-의존성의 protein kinase(PKA 및 $\mathrm{PKG})$ 를 활성화시킴으로써 세포질 내로 동원되는 $\mathrm{Ca}^{2+}$ 을 감소 하고, 혈소판의 응집을 억제한다고 알려진 바 있다(Kuo et al., 1980). 본 연구에서는 esculetin이 cAMP 및 cGMP의 cyclic nucleotides 생성에 관여하였는지 확인하였다. Fig. $2 \mathrm{~A}$ 에 나타낸 결과로 보면, esculetin에 의해 cAMP 생성이 $3.92 \pm 0.41 \mathrm{pmoL} / 10^{8}$ cells에서 $9.20 \pm 0.88 \mathrm{pmoL} / 10^{8}$ cells 까지 강하게 증가된 것을 알 수 있다. 또한, esculetin는 cGMP 생성량도 $6.53 \pm 0.46 \mathrm{pmoL} / 10^{8}$ cells에서 $8.54 \pm 0.39 \mathrm{pmoL} / 10^{8}$ cells까지 농도의존적으로 증가시킨 것을 확인하였다(Fig. 
(4)

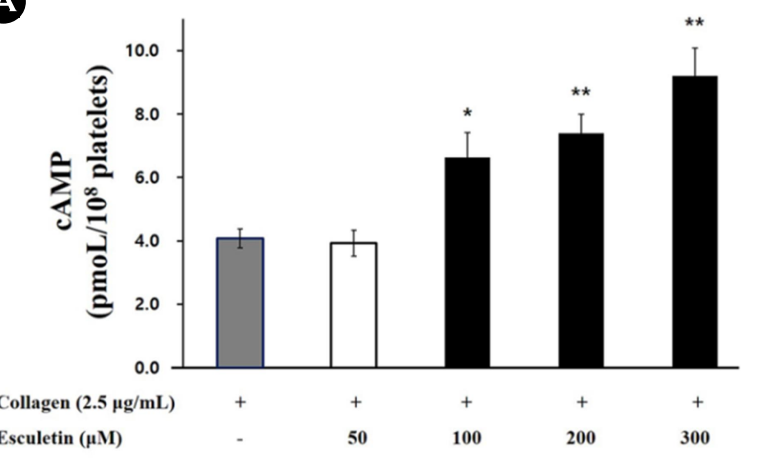

B

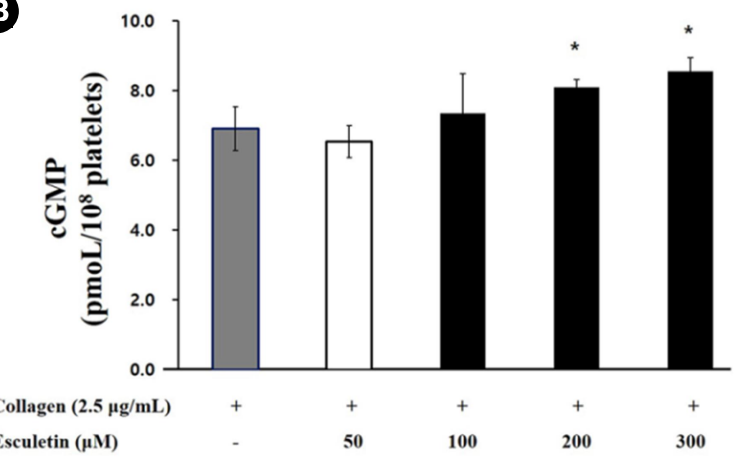

Fig. 2. Effects of esculetin on cyclic nucleotides production. (A) Effects of esculetin on cAMP production stimulated by collagen. (B) Effects of esculetin on cGMP production stimulated by collagen. Data are expressed as means $\pm \mathrm{SD}(\mathrm{n}=4)$. $* P<0.05$, $* * P<$ 0.001 compared with the collagen-stimulated platelets.

2B). 이 결과들을 통해 esculetin이 collagen 유도의 혈소판 에서 $\mathrm{cAMP}$ 및 $\mathrm{cGMP}$ 의 생성량을 농도의존적으로 강하게 증가시키면서 혈소판의 기능에 관여한다는 것을 확인하 였다.

\section{세포 내 $\mathrm{Ca}^{2+}$ 동원 및 $\mathrm{IP}_{3} \mathrm{R}$ 인산화에 미치는 esculetin의 효과}

cAMP 및 cGMP의 cyclic nucleotide이 증가할 때, 의존성 단백질 kinase인 $\mathrm{PKA}$ 및 $\mathrm{PKG}$ 를 활성화시키고, 이는 관 련된 기질들을 인산화하는 것으로 알려져 있으며, 그 중 inositol 1,4,5-triphosphate receptor $\left(\mathrm{IP}_{3} \mathrm{R}\right)$ 가 있다(Schwarz et al., 2001). $\mathrm{IP}_{3} \mathrm{R}$ 는 혈소판 내 dense tubular system에 위치하 는 $\mathrm{Ca}^{2+}$ 통로로서 inositol 1,4,5-trisphosphate $\left(\mathrm{IP}_{3}\right)$ 와 결합될 때, 세포질 내로의 $\mathrm{Ca}^{2+}$ 동원 $\left(\left[\mathrm{Ca}^{2+}\right]_{\mathrm{i}}\right)$ 을 유도한다. $\left[\mathrm{Ca}^{2+}\right]_{\mathrm{i}}$ 이 증가하면 세포골격 단백질로 알려진 myosin light chain과 pleckstrin의 인산화가 유발되게 되며, 이 때 혈소판 내 과 립 분비 및 P-selectin 발현이 일어나 혈소판 활성화 및 응
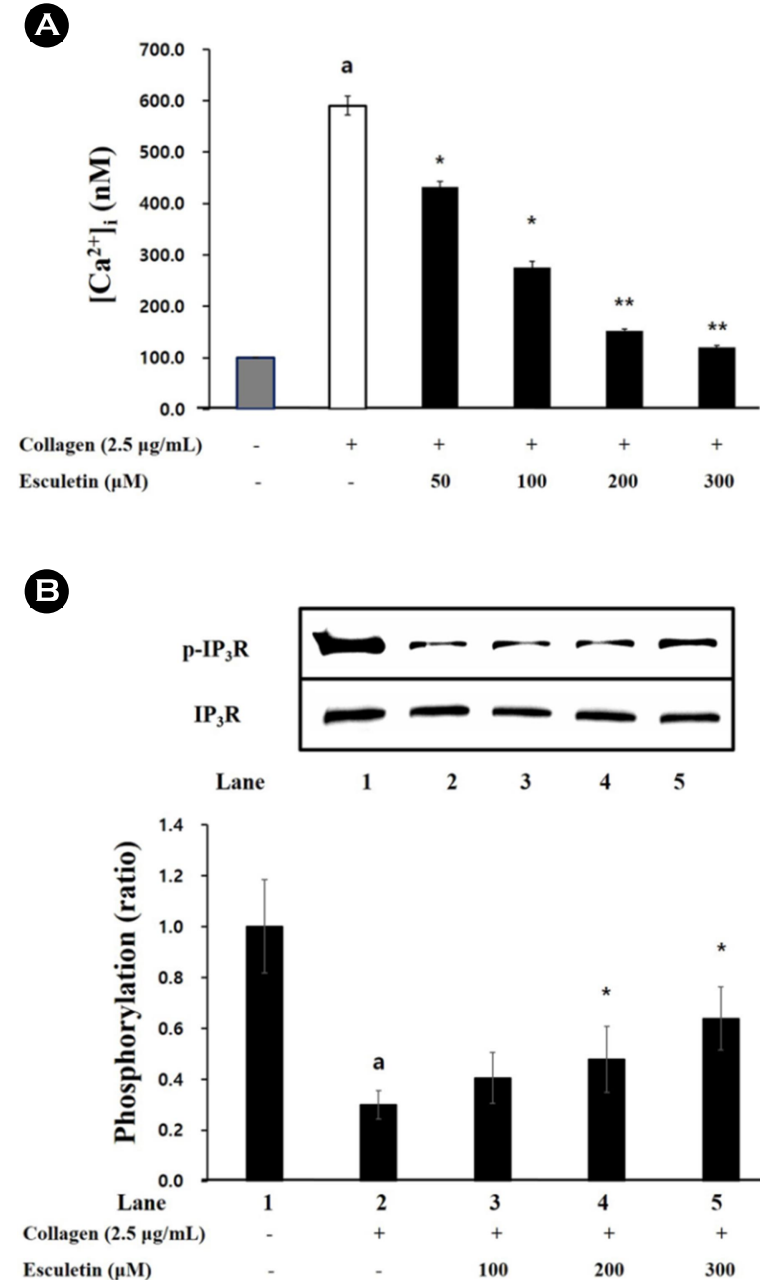

Fig. 3. Effects of esculetin on $\left[\mathrm{Ca}^{2+}\right]_{i}$ mobilization and $\mathrm{IP}_{3} \mathrm{R}$ phosphorylation. (A) Inhibitory effects of esculetin on collagen-induced $\left[\mathrm{Ca}^{2+}\right]_{\mathrm{i}}$ mobilization. (B) Effects of esculetin on collagen-induced IP3R phosphorylation. Measurement of $\left[\mathrm{Ca}^{2+}\right]_{\mathrm{i}}$ mobilization and Western blotting was described in "Materials and Methods" section. The data are expressed as the mean \pm standard deviation $(n=4)$. ${ }^{\text {a }} P<0.05$ compared with no-stimulated platelets, ${ }^{*} P<0.05$, ${ }^{* *} P<$ 0.001 compared with the collagen-stimulated platelets.

집이 되는데 중요하게 역할을 한다(VargaSzabo et al., 2009).

본 연구에서는 esculetin가 $\left[\mathrm{Ca}^{2+}\right]_{\mathrm{i}}$ 에 어떤 영향을 미치 는 지 확인하였고, 그 결과, Fig. $3 \mathrm{~A}$ 에 보여준 바와 같이, collagen에 의해 $100.7 \pm 0.3 \mathrm{nM}$ 에서 $590.6 \pm 18.3 \mathrm{nM}$ 까지 증가된 $\left[\mathrm{Ca}^{2+}\right]_{\mathrm{i}}$ 이 여러 용도의 $\operatorname{esculetin}(50,100,200$ 및 $300 \mu \mathrm{M})$ 를 첨가하였을 때 각 각 $432.5 \pm 10.0 \mathrm{nM}, 275.6 \pm$ $12.3 \mathrm{nM}, 152.1 \pm 3.2 \mathrm{nM}$ 및 $120.4 \pm 3.6 \mathrm{nM}$ 로 농도 의존적 으로 감소된 것을 알 수 있다(Fig. 3A). 그리고, esculetin 가 $\left[\mathrm{Ca}^{2+}\right]_{\mathrm{i}}$ 을 조절하는 단백질인 $\mathrm{IP}_{3} \mathrm{R}$ 의 인산화에 영향을 주었는지 확인하였고, Fig. $3 \mathrm{~B}$ 로 볼 수 있는 바와 같이, 


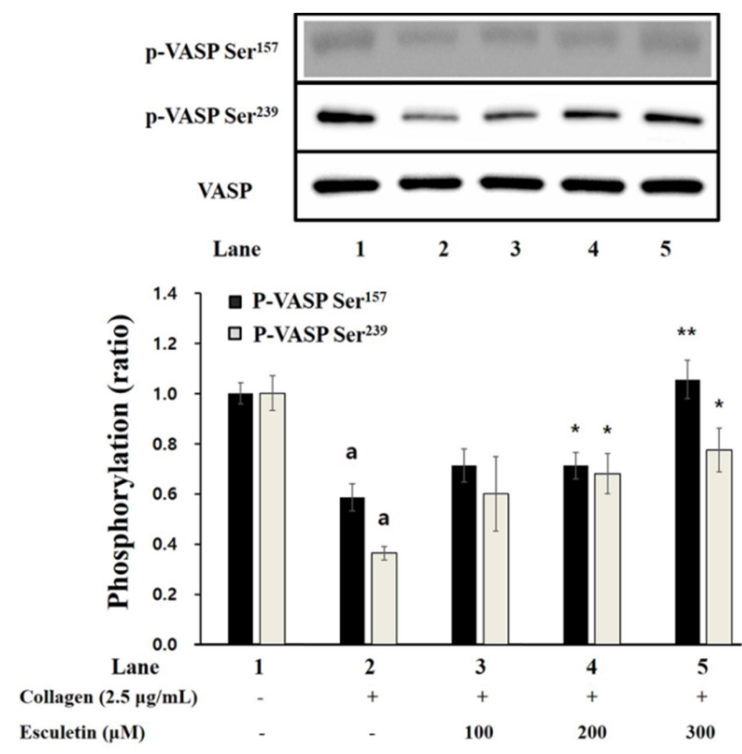

Fig. 4. Effects of esculetin on VASP phosphorylation. Western blotting was determined as described in "Materials and Methods" section. The data are expressed as the mean \pm standard deviation $(\mathrm{n}=4)$. ${ }^{\mathrm{a}} P<0.05$ compared with no-stimulated platelets, ${ }^{*} P<0.05$, ${ }^{*} P<0.001$ compared with the collagen-stimulated platelets.

esculetin이 collagen로 유도한 혈소판에서 $\mathrm{IP}_{3} \mathrm{R}$ 를 농도 의 존적으로 인산화시켰다는 것을 알 수 있다. 이 결과들은 esculetin이 cAMP/cGMP 생성 및 PKA/PKG의 활성을 증 가시켜 $\mathrm{IP}_{3} \mathrm{R}$ 의 인산화를 유도함으로써 dense tubular system 에서 세포질로 동원되는 $\mathrm{Ca}^{2+}$ 를 억제한다는 것을 보여 준다.

\section{VASP 인산화에 미치는 esculetin의 효과}

이전의 연구들을 통해, VASP가 혈소판 분비 및 점착을 조절함으로써 혈소판 활성화에 관여하는 $\mathrm{cAMP} / \mathrm{cGMP}$ 의존성 $\mathrm{PKA} / \mathrm{PKG}$ 의 주요 기질 중 하나라는 것과, VASP 의 인산화에 의해 integrin $\alpha \mathrm{Ilb} / \beta_{3}$ 의 활성화가 억제되어 혈 소판 응집을 저해한다고 알려져 있다(Napenas et al., 2013; Wangorsch et al., 2011). 본 연구에서는, collagen 유도의 혈 소판에서 esculetin에 의해 cAMP 및 cGMP 생성이 농도 의존적으로 증가된 것을 알 수 있었고(Fig. 2), 추가적으로 esculetin에 의해 cAMP-의존성의 VASP Ser ${ }^{157}$ 및 cGMP-의 존성의 VASP $\mathrm{Ser}^{239}$ 의 인산화가 어떤 영향을 받는지 확인 해 보았다. 그 결과, Fig. 4에서 나타낸 바와 같이, escultein 은 VASP Ser ${ }^{157}$ 와 VASP $\mathrm{Ser}^{239}$ 의 인산화를 농도 의존적으로 증가시켰으며, 이 결과는 escultein가 cAMP 및 cGMP의 생성을 증가시킨 것이 $\mathrm{VASP}$ 의 인산화로 이어졌다는 것
을 보여준다.

\section{$\alpha$ llb/ $\beta_{3}$ 에 대한 fibrinogen binding에 미치는 esculetin의 효과}

Integrin $\alpha \mathrm{Ilb} / \beta_{3}$ 에 의한 혈소판 내 신호 전달은 세포 골 격의 변형을 유발함으로써 혈소판 증식 및 혈전 생성을 일으키는 것으로 보고된 바 있다(Topol et al., 1999). 정상 적인 휴지기 혈소판에서는 $\alpha \mathrm{IIb} / \beta_{3}$ 가 낮은 친화도의 상태 로 존재하다가 응집유도제에 의해 혈소판이 활성화되면 inside-out 신호전달 경로를 거쳐 $\alpha \mathrm{IIb} / \beta_{3}$ 의 친화도를 증가 되는 쪽으로 구조적인 변화가 일어난다(Phillips et al., 2001). $\alpha \mathrm{IIb} / \beta_{3}$ 의 친화도가 증가되면 fibrinogen의 결합이 잘 일어 남으로써 추가적인 혈소판의 형태 변화와 점착을 통해 응 집이 촉발된다.

본 연구에서, esculetin이 fibrinogen이 $\alpha \mathrm{IIb} / \beta_{3}$ 에 결합하는 정도에 어떤 영향을 미치는지 확인하였고, collagen에 의 해 $\alpha \mathrm{IIb} / \beta_{3}$ 에 대한 fibrinogen 결합도가 $1.0 \pm 0.2 \%$ 에서 90.8 $\pm 0.5 \%$ 까지 증가되었다(Fig. 5A-b, 5B). 그러나, esculetin $(50,100,200$ 및 $300 \mu \mathrm{M})$ 을 처리하였을 때, fibrinogen의 결 합 정도가 각 각 $70.2 \pm 1.0 \%, 59.1 \pm 1.4 \%, 24.1 \pm 0.4 \%$ 및 $17.4 \pm 0.6 \%$ 까지 농도 의존적으로 억제되는 것을 확인하였 다(Fig. 5A-c f, 5B). 이는 esculetin에 의해 생성이 증가된 cyclic nucleotide들이 VASP 인산화를 유발하였고, integrin $\alpha \mathrm{IIb} / \beta_{3}$ 의 친화도를 떨어뜨림으로써 fibrinogen 결합을 억 제한 것으로 보여 진다.

\section{혈소판 매개 fibrin clot 형성에 미치는 esculetin의 효과}

Fibrin clot의 형성은 혈관의 손상된 부분이 회복되는 과 정의 마지막 단계로, 손상부위에 활성화된 혈소판이 모여 들어 30 60분간 수축을 일으키고 만들어진 plug를 당기 면서 만들어진다. 이 때, $\alpha \mathrm{Ilb} / \beta_{3}$ 에 대한 fibrinogen 결합 정 도가 혈소판이 매개한 fibrin clot 형성에서 중요하며, $\alpha \mathrm{Ilb} /$ $\beta_{3}$ 친화도를 감소시키는 물질들이 혈전 형성도 막는다고 알려져 있다(Topol et al., 1999). 또한, 혈소판 활성촉진제를 사용하여 $\alpha \mathrm{Ilb} / \beta_{3}$ 의 활성을 높이게 될 때, fibrinogen의 결합 도가 증가되어 fibrin clot이 잘 형성된다.

본 연구에서는 thrombin으로 유도한 fibrin clot 형성에서 esculetin이 미치는 효과를 확인하였고, Fig. 6A에 제시한 결과와 같이, thrombin을 처리하였을 때 fibrin clot이 강하 게 형성되었지만 esculetin에 의해 fibrin clot의 형성이 농 도 의존적으로 억제된 것을 볼 수 있다, Esculetin $(100,200$ 및 $300 \mu \mathrm{M}$ )의 억제율을 확인해 보면 각각 $10.1 \%, 47.8 \%$ 
A
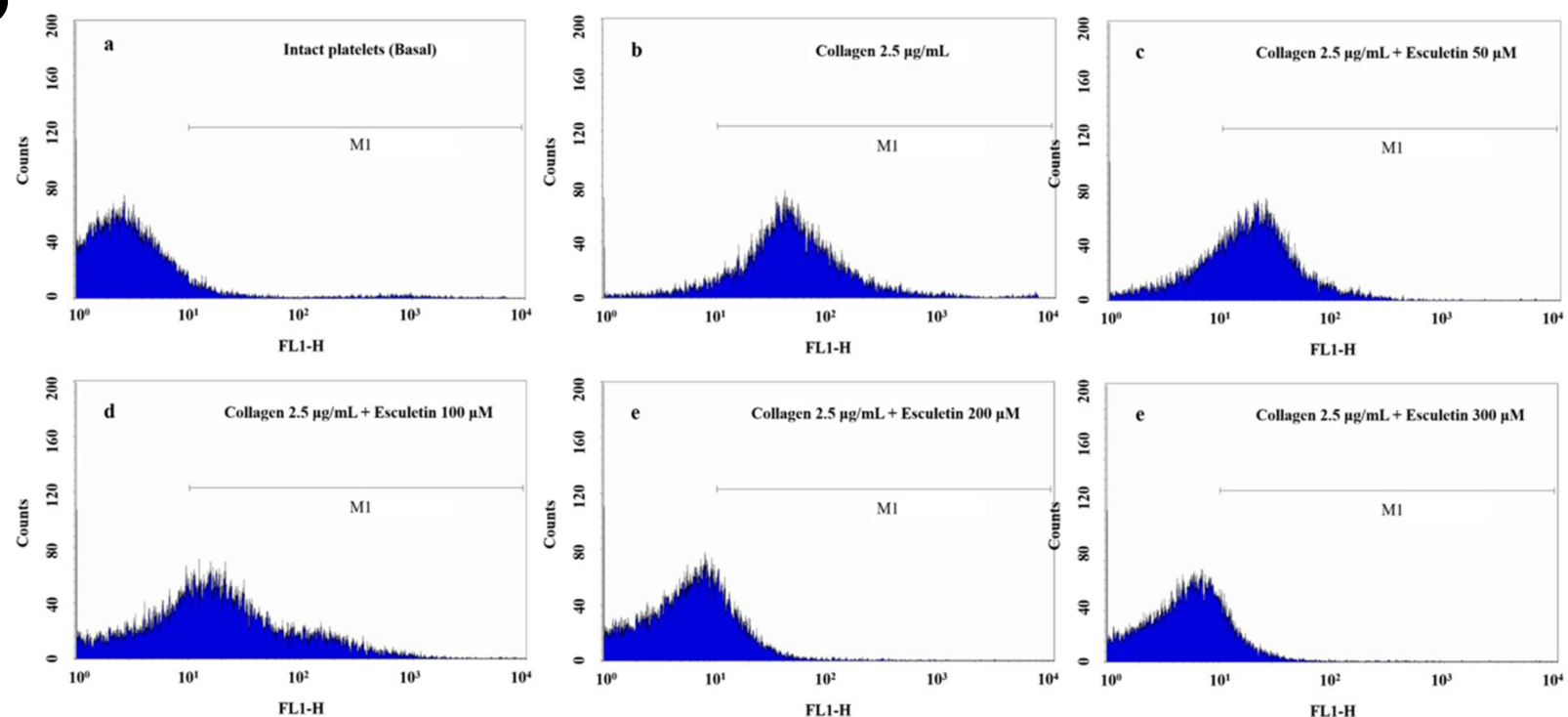

B

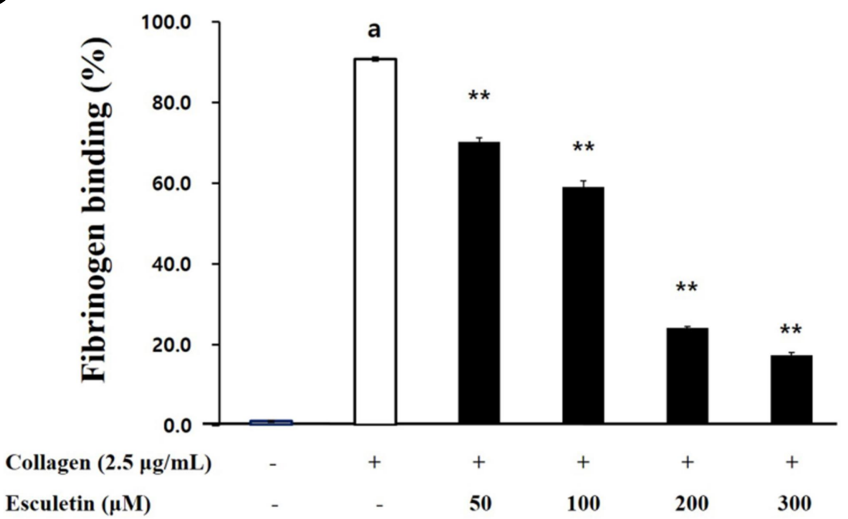

Fig. 5. Effects of esculetin on collagen-induced fibrinogen binding. (A) The flow cytometry histograms on fibrinogen binding. a, Intact platelets (base); b, collagen $(2.5 \mu \mathrm{g} / \mathrm{mL})$; c, collagen $(2.5 \mu \mathrm{g} / \mathrm{mL})+$ esculetin $(50 \mu \mathrm{M}) ; \mathrm{d}$, collagen $(2.5 \mu \mathrm{g} / \mathrm{mL})+$ esculetin $(100 \mu \mathrm{M}) ; \mathrm{e}$, collagen $(2.5 \mu \mathrm{g} / \mathrm{mL})$ + esculetin $(200 \mu \mathrm{M}) ; \mathrm{f}$, collagen $(2.5 \mu \mathrm{g} / \mathrm{mL})+$ esculetin $(300 \mu \mathrm{M})(\mathrm{B})$ Effects of esculetin on collagen-induced fibrinogen binding $(\%)$. Measurement of fibrinogen binding was described in "Materials and Methods" section. The data are expressed as the mean \pm standard deviation $(n=4)$. ${ }^{a} P<0.05$ compared with no-stimulated platelets, ${ }^{* *} P<0.001$ compared with the collagen-stimulated platelets.

A

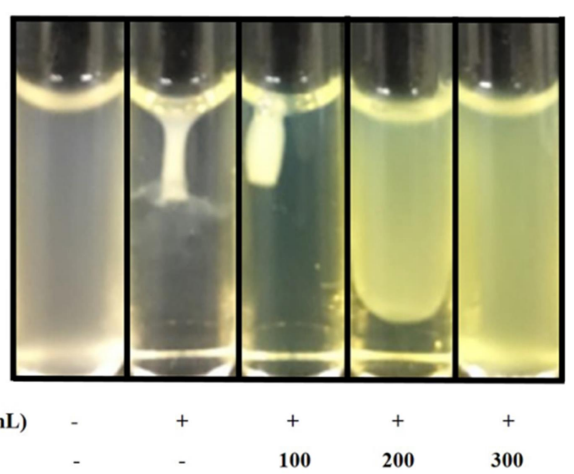

B

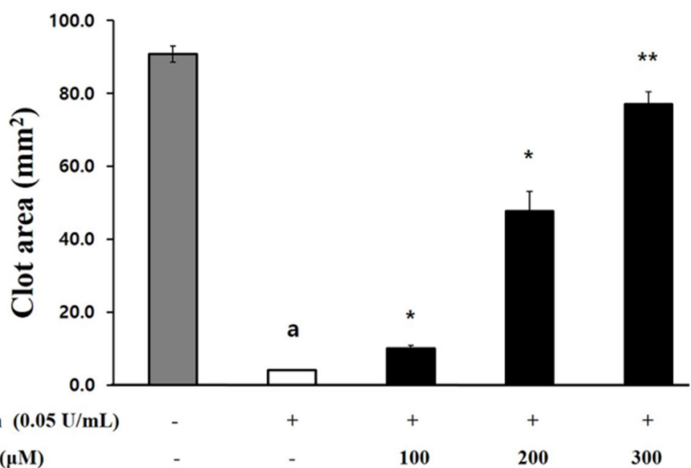

Fig. 6. Effects of esculetin on fibrin clot retraction. (A) Effects of esculetin on thrombin-retracted fibrin clot photographs (B) Effects of esculetin on thrombin-retracted fibrin clot area. Quantification of fibrin clot retraction was described in "Materials and Methods" section. The data are expressed as the mean \pm standard deviation $(\mathrm{n}=4)$. ${ }^{\mathrm{a}} P<0.05$ compared with no-stimulated platelets, ${ }^{*} P<0.05$, compared with the thrombin-stimulated platelets, $* * P<0.001$ compared with the thrombin-stimulated platelets. 
및 77.0\%로 확인되었다(Fig. 6B). 이 결과들은 esculetin가 $\mathrm{cAMP} / \mathrm{cGMP}$ 생성 증가를 통해 VASP $\mathrm{Ser}^{157} / \mathrm{VASP} \mathrm{Ser}^{239}$ 인산화를 유발하였고, $\alpha \mathrm{Ilb} / \beta_{3}$ 를 친화도를 감소시킴으로써 fibrin clot 형성 감소의 결과로 나타난 것으로 보인다.

\section{ACKNOWLEDGEMENT}

Funding for this paper was provided by Namseoul University year 2021.

\section{CONFLICT OF INTEREST}

The author declares no conflict of interest.

\section{REFERENCES}

Cavallini L, Coassin M, Borean A, Alexandre A. Prostacyclin and sodium nitroprusside inhibit the activity of the platelet inositol 1,4,5-trisphosphate receptor and promote its phosphorylation. J Biol Chem. 1996. 271: 5545-5551.

Chen H, Kahn ML. Reciprocal signaling by integrin and nonintegrin receptors during collagen activation of platelets. Mol Cell Biol. 2003. 23: 4764-4777.

Grynkiewicz G, Poenie M, Tsien RY. A new generation of $\mathrm{Ca}^{2+}$ indicators with greatly improved fluorescence properties. J Biol Chem. 1985. 260: 3440-3450.

Farndale RW. Collagen-induced platelet activation. Blood Cell Mol Dis. 2006. 36: 162-165.

Hsia CW, Lin KC, Lee TY, Hsia CH, Chou DS, Jayakumar T, Velusamy M, Chang CC, Sheu JR. Esculetin, a Coumarin Derivative, Prevents Thrombosis: Inhibitory Signaling on PLC 2 2-PKC-AKT Activation in Human Platelets. Int J Mol Sci. 2019. 20: 2731.

Jackson SP. Arterial thrombosis - insidious, unpredictable and deadly. Nat Med. 2011. 17: 1423-1436.

Kantarcioglu B, Iqbal O, Walenga JM, Lewis B, Lewis J, Carter CA, et al. An Update on the Pathogenesis of COVID-19 and the Reportedly Rare Thrombotic Events Following Vaccination. Clin Appl Thromb Hemost. 2021. 27: 10760296211021498.

Karthika P, Rajadurai M, Ganapathy P, Kanchana G. Preventive effect of esculetin on lipid peroxides and antioxidants in isoproterenol-induced myocardial infarction in Wistar rats. $\mathrm{J}$ Pharm Res. 2012. 5: 915-918.

Kuo JF, Andersson RG, Wise BC, Mackerlova L, Salomonsson I, Brackett NL, et al. Calcium-dependent protein kinase: widespread occurrence in various tissues and phyla of the animal kingdom and comparison of effects of phospholipid, calmodulin, and trifluoperazine. Proc Natl Acad Sci. 1980. 77: 70397043 .

Laurent V, Loisel TP, Harbeck B, Wehman A, Gröbe L, Jockusch $\mathrm{BM}$, et al. Role of proteins of the Ena/VASP family in actinbased motility of Listeria monocytogenes. J Cell Biol. 1999. 144: 1245-1258.

Liang C, Ju W, Pei S, Tang Y, Xiao Y. Pharmacological activities and synthesis of esculetin and its derivatives: A mini-review. Molecules. 2017. 22: 387.

Napeñas J, Oost FC, DeGroot A, Loven B, Hong CH, Brennan MT, et al. Review of postoperative bleeding risk in dental patients on antiplatelet therapy. Oral Surg Oral Med Ora Pathol Oral Radiol. 2013. 115: 491-499.

Phillips DR, Nannizzi-Alaimo L, Prasad KS. Beta3 tyrosine phosphorylation in alphaIIbbeta3 (platelet membrane GP IIb-IIIa) outside-in integrin signaling. Thromb Haemost. 2001. 86: 246258.

Quinton TM, Dean WL. Cyclic AMP-dependent phosphorylation of the inositol-1,4,5-trisphosphate receptor inhibits $\mathrm{Ca}^{2+}$ release from platelet membranes. Biochemical and Biochem Biophys Res Commun. 1992. 184: 893-899.

Schwarz UR, Walter U, Eigenthaler M. Taming platelets with cyclic nucleotides. Biochem Pharmacol. 2001. 62: 1153-1161.

Shin JH, Kwon HW, Lee DH. Ginsenoside F4 inhibits platelet aggregation and thrombus formation by dephosphorylation of IP $_{3}$ RI and VASP. J Appl Biol Chem. 2019. 62: 93-100.

Sudo T, Ito H, Kimura Y. Phosphorylation of the vasodilatorstimulated phosphoprotein (VASP) by the anti-platelet drug, cilostazol, in platelets. Platelets. 2003. 14: 381-390.

Topol EJ, Byzova TV, Plow EF. Platelet GPIIb-IIIa blockers. The Lancet. 1999. 353: 227-231.

VargaSzabo D, Braun A, Nieswandt B. Calcium signaling in platelets. J Thromb Haemost. 2009. 7: 1057-1066.

Wangorsch G, Butt E, Mark R, Hubertus K, Geiger J, Dandekar T, et al. Time-resolved in silico modeling of finetuned cAMP signaling in platelets: feedback loops, titrated phosphorylations and pharmacological modulation, BMC Syst Biol. 2011. 5: 178.

https://doi.org/10.15616/BSL.2021.27.4.270

Cite this article as: Lee DH. Thrombus Formation Inhibition of Esculetin through Regulation of Cyclic Nucleotides on Collagen-Induced Platelets. Biomedical Science Letters. 2021. 27: 270-276. 